\title{
BMJ Open Social and life skills in adolescents who have self-harmed: analysis of survey responses from a national sample of adolescents in Norway
}

\author{
Elin Anita Fadum (D) , ${ }^{1}$ Ellen Øen Carlsen, ${ }^{1,2}$ Maria Ramberg, ${ }^{3}$ Leif Aage Strand, \\ Siri Eldevik Håberg, ${ }^{1,4}$ Einar Borud, ${ }^{1,5}$ Monica Martinussen ${ }^{6,7}$
}

To cite: Fadum EA, Carlsen EØ, Ramberg $\mathrm{M}$, et al. Social and life skills in adolescents who have self-harmed: analysis of survey responses from a national sample of adolescents in Norway. BMJ Open 2021;11:e054707. doi:10.1136/ bmjopen-2021-054707

\section{- Prepublication history for} this paper is available online. To view these files, please visit the journal online (http://dx.doi. org/10.1136/bmjopen-2021 054707).

Received 21 June 2021 Accepted 14 October 2021

A Check for updates

(c) Author(s) (or their employer(s)) 2021. Re-use permitted under CC BY-NC. No commercial re-use. See rights and permissions. Published by BMJ.

For numbered affiliations see end of article.

Correspondence to Dr Elin Anita Fadum; efadum@forsvaretshelser egister.no

\section{ABSTRACT}

Objective Social and life skills (SLS) may be important in the prevention and treatment of self-harm, but few studies have described this relationship. We examined three components of SLS in adolescents who reported self-harm that was, according to themselves, diagnosed by a clinician.

Design Cross-sectional.

Setting National screening prior to military service. Participants 176284 residents of Norway born in 1999-2001 received a declaration of health. We included 171486 individuals (84 153 (49\%) women and 87333 (51\%) men) who were $17(n=167855)$ or 18 years of age $(n=3631)$ when they completed the declaration.

Outcome measure The main outcome was clinically diagnosed self-harm, defined as self-harm that the adolescents themselves stated had been diagnosed by a clinician. Components of SLS were social interactions; coping strategies; and emotional regulation/aggression. The association between SLS and self-reported clinically diagnosed self-harm was assessed in hierarchical multiple regression models controlling for sex; school absence; and feelings of emotional pain.

Results Three percent $(n=5507)$ of the adolescents reported clinically diagnosed self-harm. The three components of SLS together added little to the prediction of clinically diagnosed self-harm $\left(\Delta R^{2}=0.02\right)$. After controlling for school absence and emotional pain, emotional regulation/aggression was the only SLScomponent that was independently associated with clinically diagnosed self-harm (OR 1.33, 95\% $\mathrm{Cl} 1.31$ to 1.36). The young men who said they had been clinically diagnosed for self-harm scored slightly worse on social interactions (Hedge's $g(g)=-0.13, p<0.001$ ) and emotional regulation/aggression $(g=-0.18, p<0.001)$ than the young women in this group.

Conclusion Young women and young men who reported clinically diagnosed self-harm had more problems with emotional regulation/aggression than other adolescents, but did not have worse social interactions or coping strategies.

\section{INTRODUCTION}

Self-harm among adolescents is a serious public health problem. The prevalence of
Strengths and limitations of this study

- This study examined adolescents who engaged in self-harm in a near complete national cohort of adolescents.

- Among those who were invited, $97 \%$ submitted their responses, and close to $90 \%$ of all 17 years olds who lived in Norway in 2016-2018 participated.

- The topic of self-harm was very crude and only asked to the respondents who stated that self-harm had been diagnosed by a clinician

- The questionnaire did not include a full scale on social and life skills.

self-harm in this population has been estimated at around $15 \%$ and is constantly increasing. ${ }^{12}$ Adolescents who self-harm often experience psychosocial difficulties later in life $^{3}$ and are at increased risk of premature death, particularly by suicide, alcohol or drug overdose. ${ }^{45}$ Important contributors to self-harm include sexual or physical abuse, trauma, familial problems and psychiatric disorders. ${ }^{6}$ Most of the current research on the topic is based on biopsychosocial frameworks that demonstrate the complex pathways of self-harm. These models show how social vulnerability interacts with an individual's biological predispositions and psychological characteristics, and demonstrate how factors such as sex, emotional regulation capacity and impulsivity moderate and mediate the associations between negative life events and self-harm. ${ }^{6-8}$

No effective interventions against selfharming behaviour have been established, but dialectical behavioural therapy and developmental group therapy have shown promise. $^{9} 10$ Moreover, some evidence suggests that self-harm among adolescents can be reduced by improving psychosocial environments in schools. ${ }^{11}$ 
The idea that self-harm can be prevented through community and friendships builds on key theories in suicidology, which claim that self-harm may occur in response to lower social integration or invalidating emotional environments. ${ }^{12-15}$ Young people are usually able to acquire a range of social and life skills (SLS) that allow them to connect with, interact with, and relate positively to other people, ${ }^{16}$ and that are applicable across a wide range of contexts in daily life and risk situations. The most important SLS are usually considered to be selfawareness; empathy; communication and interpersonal skills; and coping with emotions and stress. ${ }^{16}$ However, adolescents who self-harm tend to have worse scores on these important SLS; they are usually poor problem solvers with limited access to communication and inadequate emotional regulating strategies. ${ }^{17} 18$ Because adolescents who self-harm often respond to internal or external stimuli with rapid and impulsive reactions, ${ }^{19}$ it may be hard for them to make well-considered, socially acceptable choices. They frequently report difficulties in making new friends, arguments with others, loneliness, interpersonal isolation and/or bullying. ${ }^{20} 21$

Despite the fact that self-harm in adolescence is closely associated with psychiatric problems and may lead to severe outcomes, few adolescents seek medical or psychological treatment for this behaviour. ${ }^{122}$ Moreover, many patients who self-harm are not correctly diagnosed with this behaviour. ${ }^{23}$ Interventions that aim to strengthen SLS $^{2425}$ may help prevent and treat self-harm, as improved SLS may help adolescents buffer difficult emotions, diminish the negative social consequences of self-harm, and increase communication and help-seeking behaviour. However, the mechanisms by which SLS may influence self-harm have not been thoroughly explored. ${ }^{7}$ Studies that describe SLS among self-harming adolescents are an important step in identifying the most effective treatment and preventive strategies.

The present study investigated SLS in adolescents who reported having received a diagnosis of self-harm from a clinician in a nearly complete national population of adolescents. Our first aim was to characterise SLS in those who reported clinically diagnosed self-harm and to compare their SLS with adolescents who did not report clinically diagnosed self-harm. We hypothesised that those who reported clinically diagnosed self-harm would have less favourable scores on SLS components.

It is well known that most adolescents who self-harm suffer from significant emotional pain. ${ }^{6}$ Furthermore, there is emerging evidence of an association between school absence and self-harm. ${ }^{26}$ Emotional pain and school-absenteeism has many negative effects on social functioning and may hinder the social training that usually happens in school. ${ }^{25}$

We wanted to examine to what extend components of SLS contributed to the prediction of clinically diagnosed self-harm when such emotional and functional problems were considered. Lastly, because there are clear sex differences in self-harming behaviour, impulsivity, and coping among adolescents, ${ }^{78}$ we examined SLS among those who reported clinically diagnosed self-harm in sexstratified analyses.

\section{MATERIAL AND METHODS}

In Norway, pursuant to the Defence Act, any person residing in the country who reaches the age of 17 must submit a declaration of health to the Armed Forces' Human Relations and Conscription Center (AFHRCC), which is used for military selection. In principle, all citizens are eligible to serve, but the AFHRCC does collect some information about health, education, and social security benefits and penalties from various registries to identify anyone unfit for military service, and these individuals are exempt from completing the declaration. The declaration is internet-based; respondents must identify themselves with an electronic personal identification number before they complete the declaration, and they must confirm that they understand that incorrect answers can lead to criminal liability under the law. Data from the declarations are stored in the Norwegian Armed Forces Health Registry (NAFHR) and are available for research that is in accordance with the purpose of the registry and international ethical guidelines for medical research. ${ }^{27-29}$

\section{Participants}

In 2016-2018, 176284 residents of Norway born in 1999-2001 received the declaration of health from the AFHRCC. We included 171486 persons (84 153 young women, $49 \%$; 87333 young men, $51 \%)$ who were $17(\mathrm{n}=1$ $67855)$ or 18 years of age $(n=3631)$ when they completed the declaration. The study sample represented $97 \%$ of those who received the declaration and $87 \%$ of all 17-year-olds registered as residents during the 3-year study period. ${ }^{30}$

\section{Measures}

Self-harm

In the declaration, adolescents were presented with a list of 23 conditions and were asked to check only the conditions for which they had received diagnosis from a clinician. Those who checked 'self -harm' (have you harmed yourself intentionally?) were categorised as having clinically diagnosed self-harm.

\section{School absence and emotional pain}

Questions on school absence and emotional pain were as follows:

Have you been absent from school/work over a total of 8 weeks due to injury or illness in the last 12 months? (No/Yes, but I have fully recovered/Yes, and I have not recovered).

Do feelings of anxiety, mental distress or depression negatively affect your daily life? (No/Yes, but very little/Yes, significantly/Yes, I receive treatment for this). 
School absence was coded 1-3 and emotional pain was coded 1-4 $(1=\mathrm{No})$.

\section{Social and life skills}

The adolescents assessed how well they felt and functioned socially by rating their agreement with 11 statements about social life, stress, emotional regulation and aggression on a four-point scale ( $1=$ strong agreement, 4=strong disagreement). Eight of the statements were formulated in a positive way (ie, I usually feel well when I am at school and with friends) thus lower scores indicated better skills. The remaining questions were formulated so that lower scores indicated more problem behaviour; therefore, we reversed the scores on these three questions before computing the total score for the scale.

In order to reduce the number of items, we conducted a principal component analysis (PCA), applying Jolliffes' criterion $^{31}$ and Varimax rotation. The Kaiser-Meyer-Olkin measure of sampling adequacy was 0.86 . An inspection of the scree plot revealed a break after the third component, thus we decided to use three components-social interactions, coping strategies, and emotional regulation/aggression-for further investigation. This three-component solution explained $59 \%$ of the total variance. Social interactions, contributed $23 \%$ to the variance, and included four items about friends and getting along with other people. Coping strategies consisted of three items about taking initiative, sense of responsibility, and coping with stress, and explained $19 \%$ of the variance. Finally, emotional regulation/aggression was constructed from three questions about anger, fighting, and self-control, and explained 15\% of the variance. One item about sleeping problems loaded equally on the second and third component, and was omitted from further analyses. Cronbach's alpha $(\alpha)$ for social interaction was $0.79 ; \alpha=0.73$ for coping strategies; and $\alpha=0.52$ for emotional regulation/aggression. We constructed a sum-score for each of the three components of SLS by adding the values of the items included. Higher scores indicating worse social interactions, worse coping strategies, and worse emotional regulation/less aggression.

\section{Statistical analyses}

All variables were analysed as continuous variables. We used descriptive statistics to investigate school absence, emotional pain, and the three components of SLS in adolescents who reported clinically diagnosed self-harm compared with those who did not. Pearson's $\chi^{2}$ test and Mann Whitney U-test were used to test for statistically significant differences between groups. Effect sizes for mean group differences were calculated in terms of Hedges' $\mathrm{g}(\mathrm{g}) .^{32}$ Because our study sample had a narrow age-range, age was not included in the analyses. Univariate descriptive analyses are presented in table 1 .

Hierarchical multiple regression with robust standard errors was conducted to assess whether, and to what extent, worse scores on social interactions, coping strategies, and emotional regulation/aggression were associated with reporting clinically diagnosed self-harm after controlling for school absence and emotional pain (tables 2 and 3). Sex and school absence were entered in the first step (model 1), emotional pain was included in the second step (model 2), and social interaction, coping strategies, and emotional regulation/aggression were entered in the third and last step (model 3). We examined possible sex differences by rerunning the multivariate analyses stratified by sex and comparing young men and women who reported clinically diagnosed self-harm, using descriptive statistics and logistic regression. The analyses were performed in Stata V.14.2, StataCorp LLC, Texas, USA.

Table 1 Differences in social and life skills between adolescents who did and did not report clinically diagnosed self-harm

\begin{tabular}{|c|c|c|c|c|c|c|c|c|}
\hline & \multicolumn{2}{|c|}{$\begin{array}{l}\text { Total } \\
N=171486\end{array}$} & \multicolumn{2}{|c|}{$\begin{array}{l}\text { Did not report clinically } \\
\text { diagnosed self-harm } \\
n=165979(96.79 \%)\end{array}$} & \multicolumn{2}{|c|}{$\begin{array}{l}\text { Reported clinically } \\
\text { diagnosed self-harm } \\
n=5507(3.21 \%)\end{array}$} & \multirow[b]{2}{*}{ Hedges'g } & \multirow[b]{2}{*}{ P value } \\
\hline & Mean & SD & Mean & SD & Mean & SD & & \\
\hline $\begin{array}{l}\text { School } \\
\text { absence } \\
>8 \text { weeks in } \\
\text { the last year }\end{array}$ & 0.05 & 0.31 & 0.04 & 0.29 & 0.24 & 0.63 & -0.64 & $<.001$ \\
\hline $\begin{array}{l}\text { Social } \\
\text { interactions }\end{array}$ & 6.1 & 2.11 & 6.05 & 2.07 & 7.68 & 2.64 & -0.77 & $<.001$ \\
\hline $\begin{array}{l}\text { Coping } \\
\text { strategies }\end{array}$ & 5.87 & 2.02 & 5.82 & 2.00 & 7.17 & 2.18 & -0.66 & $<.001$ \\
\hline
\end{tabular}


Table 2 Hierarchical logistic regression results for predicting self-reported clinically diagnosed self-harm $(\mathrm{N}=171486)$

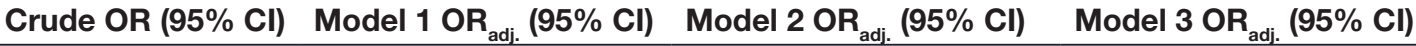

\begin{tabular}{lllll}
\hline Sex & & & & \\
$\quad$ Female & Ref. & Ref. & Ref. & Ref. \\
\hline Male & $0.19(0.18$ to 0.21$)$ & $0.20(0.19$ to 0.22$)$ & $0.34(0.32$ to 0.37$)$ & 0.31 (0.29 to 0.34$)$ \\
School absence & $2.56(2.45$ to 2.68$)$ & $2.36(2.26$ to 2.47$)$ & $1.04(0.99$ to 1.10$)$ & 1 (0.94 to 1.06$)$ \\
Emotional pain & $3.77(3.68$ to 3.86$)$ & & $3.44(3.35$ to 3.52$)$ & 3.02 (2.94 to 3.11$)$ \\
Social interaction & $1.33(1.30$ to 1.32$)$ & & 1.01 (0.99 to 1.03$)$ \\
Coping strategies & $1.33(1.32$ to 1.35$)$ & & & $1.00(0.98$ to 1.01$)$ \\
Emotional regulation/ & $1.65(1.63$ to 1.68$)$ & & 0.176 & $1.33(1.31$ to 1.36$)$ \\
aggression & & & 0.252 & 0.021 \\
Delta R2 & & 0.076 & & 0.273 \\
Pseudo R2 & & & &
\end{tabular}

Patient and public involvement

We did not include patient or public involvement in the conduction of the present study.

\section{RESULTS}

$3.2 \%(\mathrm{n}=5507)$ of our sample of Norwegian adolescents reported clinically diagnosed self-harm; $5.4 \%$ of young women $(n=4538)$ and $1.1 \%$ of young men $(n=969)$. The majority $(n=4763,86.5 \%)$ of these adolescents reported some degree of emotional pain, compared with $23.6 \%$ ( $n=39$ 201) of those who did not report clinically diagnosed self-harm. Furthermore; adolescents who reported clinically diagnosed self-harm had more school absence compared with those who did not (table 1).
SLS in adolescents who did and did not report clinically diagnosed self-harm

In bivariate analyses, adolescents who reported clinically diagnosed self-harm had worse scores on social interactions; coping strategies; and emotional regulation/ aggression than those who did not report clinically diagnosed self-harm (table 1 and figure 1). The differences were medium to large according to Cohen's labels (1988) for effect sizes.

The components of SLS correlated with emotional pain with medium strength. Pearson correlation coefficients (r) were: $r=0.37$ (social interactions), $r=0.33$ (coping strategies), $\mathrm{r}=0.31$ (emotional regulation/aggression) (all $\mathrm{p} \leq 0.001)$. Correlations between SLS and school absence were small, but statistically significant with $\mathrm{p} \leq 0.001$.

\begin{tabular}{|c|c|c|c|}
\hline Female ( $\mathrm{N}=84153)$ & Crude OR (95\% CI) & Model $1 \mathrm{OR}_{\mathrm{adj} .}(95 \% \mathrm{Cl})$ & Model 2 OR $_{\text {adj. }}(95 \% \mathrm{Cl})$ \\
\hline School absence & 2.30 (2.18 to 2.41$)$ & 1.06 (1.007 to 1.13$)$ & $1.02(0.96$ to 1.09$)$ \\
\hline Emotional pain & 3.28 (3.19 to 3.38$)$ & 3.25 (3.16 to 3.34$)$ & 2.88 (2.80 to 2.97$)$ \\
\hline Social interaction & 1.28 (1.26 to 1.29$)$ & & $1(0.99$ to 1.02$)$ \\
\hline Coping strategies & 1.30 (1.28 to 1.31$)$ & & $1(0.98$ to 1.02$)$ \\
\hline Emotional regulation/aggression & 1.73 (1.70 to 1.76$)$ & & 1.33 (1.30 to 1.37$)$ \\
\hline Delta R2 & & 0.187 & 0.02 \\
\hline Pseudo R2 & & 0.209 & 0.23 \\
\hline Male (N = 87 333) & Crude OR (95\% Cl) & Model 1 OR $_{\text {adj. }}(95 \% \mathrm{Cl})$ & Model 2 OR $_{\text {adj. }}(95 \% \mathrm{Cl})$ \\
\hline School absence & 2.75 (2.47 to 3.07$)$ & $0.93(0.82$ to 1.05$)$ & $0.88(.78$ to 1$)$ \\
\hline Emotional pain & 4.22 (3.99 to 4.45$)$ & 4.26 (4.05 to 4.5$)$ & 3.67 (3.44 to 3.91$)$ \\
\hline Social interaction & $1.37(1.34$ to 1.41$)$ & & 1.03 (0.99 to 1.07$)$ \\
\hline Coping strategies & 1.41 (1.37 to 1.45$)$ & & 1 (0.96 to 1.04$)$ \\
\hline Emotional regulation/aggression & $1.66(1.61$ to 1.71$)$ & & $1.32(1.27$ to 1.37$)$ \\
\hline Delta R2 & & 0.191 & 0.023 \\
\hline Pseudo R2 & & 0.212 & 0.235 \\
\hline
\end{tabular}


Social interactions
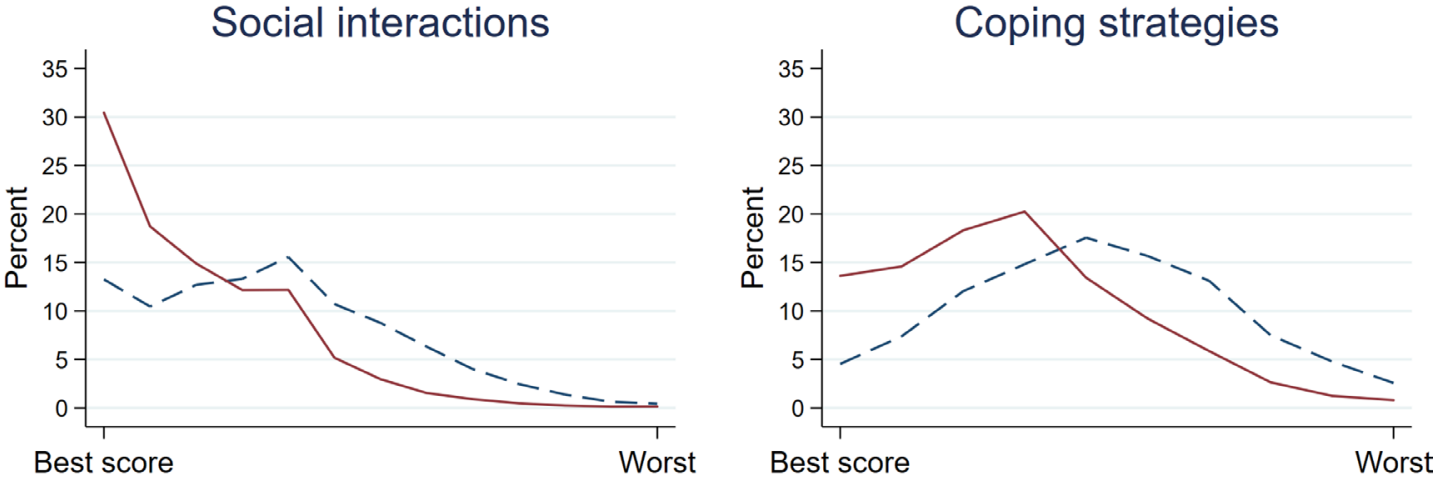
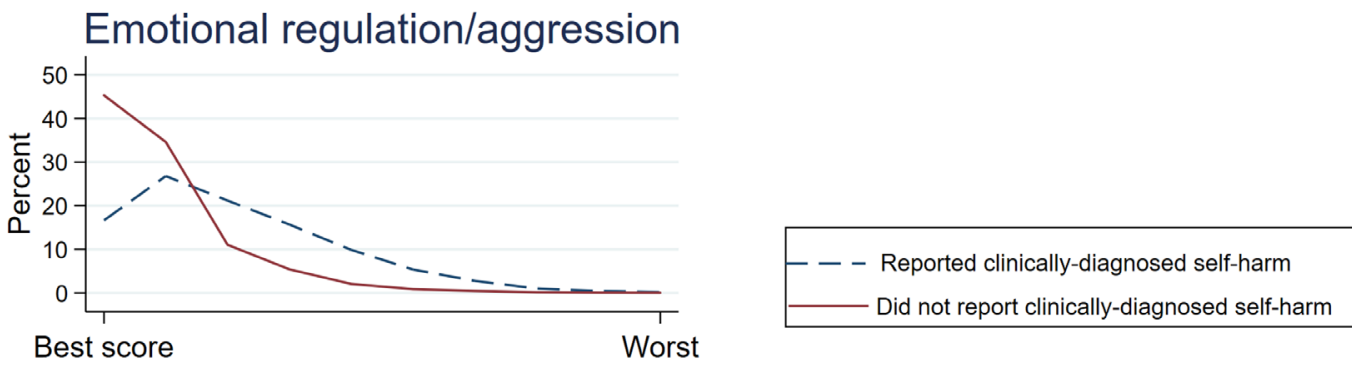

Figure 1 Components of social and life skills in Norwegian adolescents presented as percentages with best and worst scores in adolescents who did and did not report clinically diagnosed self-harm, $N=171486$.

In hierarchical multiple regression, emotional pain had a statistically significant contribution to the prediction of self-reported clinically diagnosed self-harm $\left(\Delta \mathrm{R}^{2}=0.17\right)$ $(F(1,171486)=9651.29, \mathrm{p} \leq 0.001) \quad($ table 2$)$. Conversely, the inclusion of the three SLS components contributed only a small amount $(2 \%, F(3,171486)=1021.39$, $\mathrm{p} \leq 0.001)$, and reduced the strength of the association between emotional pain and self-reported clinically diagnosed self-harm by $12 \%$. Among the three components of SLS, only emotional regulation/aggression remained statistically significantly associated with self-reported clinically diagnosed self-harm in the full model (model 3). This was true for both sexes (table 3).

\section{Sex differences in SLS in adolescents who reported clinically diagnosed self-harm}

About half of young men $(n=535,55.2 \%)$ and a similar portion of young women $(n=2411,53.1 \%)$ who reported clinically diagnosed self-harm said that they were little or significantly disturbed by emotional pain on a daily basis. However, significantly fewer young men received treatment for this: $25 \%$ versus $35 \%$ of young women (245 men and 1572 women). Consequently, more young men than young women who reported clinically diagnosed self-harm said that they were not disturbed by emotional pain daily (respectively $189(19.5 \%)$ of the men and 555 $(12.2 \%)$ of the women $\left(\chi^{2}(3, \mathrm{n}=5507)=53.2, \mathrm{p} \leq 0.001\right)$. Young men who reported clinically diagnosed self-harm had worse social interactions and a worse ability to regulate emotions/aggression than young women in this group. Nevertheless, sex differences were generally small or insignificant (table 4).

\section{DISCUSSION}

This national comprehensive study included close to $90 \%$ of all 17 years olds who lived in Norway at the study period. Three per cent of the adolescents reported clinically diagnosed self-harm, that is, that they themselves

Table 4 Social and life skills in adolescents who reported clinically diagnosed self-harm by sex, $n=5507$

\begin{tabular}{|c|c|c|c|c|c|c|c|c|}
\hline & \multicolumn{6}{|c|}{ Descriptive statistics } & \multirow{2}{*}{\multicolumn{2}{|c|}{$\begin{array}{l}\text { Logistic regression } \\
\text { Female = reference }\end{array}$}} \\
\hline & \multicolumn{2}{|c|}{ Female } & \multicolumn{2}{|l|}{ Male } & \multirow[b]{2}{*}{$P$ value } & \multirow[b]{2}{*}{ Hedges'g } & & \\
\hline & Mean & SD & Mean & SD & & & OR $_{\text {adj }}$ & $95 \% \mathrm{Cl}$ \\
\hline Emotional pain & 2.82 & 1.04 & 2.56 & 1.06 & $<.001$ & 0.20 & 0.70 & 0.65 to 0.76 \\
\hline Social interaction & 7.62 & 2.6 & 7.97 & 2.77 & $<.001$ & -0.13 & 1.06 & 1.03 to 1.10 \\
\hline Emotional regulation/aggression & 5.06 & 1.65 & 5.37 & 1.89 & $<.001$ & -0.18 & 1.12 & 1.07 to 1.17 \\
\hline
\end{tabular}


reported having received a diagnosis of self-harm from a clinician. The majority of these adolescents were more often disturbed by mental distress, anxiety and depression and they were less able to regulate negative emotions and aggression than other adolescents. However, worse social interactions and worse coping strategies added little to the prediction of self-reported clinically diagnosed selfharm, and the sex differences in our results were few and small.

Surveys estimate that $15 \%-20 \%$ of adolescents selfharm, and among these, 10\%-20\% contact healthcare services. ${ }^{12}$ Based on these estimates, the portion of adolescents who reported clinically diagnosed self-harm in this study is within the expected range, but no data for exact comparison are available. The characteristics of the adolescents who reported clinically diagnosed self-harm are concurrent with well-established knowledge that self-harm is strongly associated with intense emotional pain, worse social relations, worse coping strategies and more impulsivity. ${ }^{6} 171921$ The small sex differences we found about SLS in clinically diagnosed self-harm tended towards previous research that observed more aggression among self-harming young men than young women. ${ }^{25} 33$

In our study, both young men and young women who reported clinically diagnosed self-harm experienced more emotional rather than social problems when compared with other adolescents, and social interactions and coping strategies did not seem to buffer the emotional pain to any appreciable degree. This could support the hypothesis that coping changes inversely with depression in selfharming adolescents, ${ }^{18}$ or it could be due to limitations in the measurements in our study. It is possible that those who reported clinically diagnosed self-harm had received treatment, which may have improved their SLS to the level of the reference group at the time they submitted their health declaration. ${ }^{24}$ However, we did not have information on the timing of self-harm. Nor did we have access to records on their medical treatment and cannot tell whether they had received any psychiatric treatment or SLS training. Most likely, those who reported clinically diagnosed self-harm had various types of healthcare contacts, treatment, and follow-up, which most likely had various impacts on their SLS. Alternatively, it is possible that the SLS of adolescents who reported clinically diagnosed self-harm in our study did not differ from those of other adolescents in the first place. Facilitators of helpseeking behaviour include social support and encouragement from others. ${ }^{13435}$ Thus, it is plausible that factors such as social relations, communication skills, initiative, and less aggression are core characteristics of those selfharming adolescents who actually get in contact with healthcare.

The lack of clear sex differences in SLS that we observed was very interesting. It could be related to our study methods, for example, the items on which emotional regulation/aggression was based may have captured anger expressed outwardly, which is more typical of boys and men, better than internal anger, which is more typical in young women. ${ }^{33}$ However, we speculate that common sex differences in self-harm and its associated factors are more evident in the less severe part of the behavioural spectrum. It may be that boys who have mild emotional difficulties do not engage in self-harm directly, but rather regulate their distress and even inflict pain on themselves by participating in antisocial, risky or athletic activities where they are exposed to physical strain, injuries, or accidents. ${ }^{36}$ Moreover, in terms of social function and aggression, sex may be a less important factor among those who suffer so much that they recognise their behaviour as self-harm, take the step to seek treatment, and actually have their condition recognised and diagnosed by a clinician.

\section{Strengths}

To our knowledge, no previous study has examined selfharm that most likely had been clinically treated in a near complete national cohort of adolescents. The data in this study were collected by the Norwegian Armed Forces. Adolescents were obligated to submit their declaration of health by law; they knew that they could be called in for an in-person medical examination to verify their answers, and they knew that giving incorrect information could have consequences, which minimises the risk of selection and reporting bias. Most previous cohort studies and cross-sectional surveys have been conducted among students in selected schools. ${ }^{1}$ Therefore, we argue that the present study adds to the existing literature through its increased generalisability and validity compared with previous research.

\section{Limitations}

The results of this study must be interpreted in light of some limitations. The cross-sectional design implies that we cannot determine the directionality of the associations between SLS and clinically diagnosed self-harm. Moreover, the questionnaire that we used was developed for military selection and not for research purposes, which has implications for the measures and limited the analyses in our study. The topic of self-harm in the declaration was very crude and only asked to the respondents who could state that the self-harm had been diagnosed by a clinician. Consequently, our reference group included adolescents who self-harmed but had not been diagnosed by a clinician. Therefore our risks are most likely underestimated, and cannot be generalised to the majority of self-harming adolescents who do not contact healthcare or do not receive a clinical diagnosis for self-harm. ${ }^{138}$ We did not control for other mental disorders. Neither could we investigate SLS with respect to self-harming methods, frequency of self-harm, suicide intention, helpseeking behaviour, or treatment. The questionnaire did not include a full SLS scale. We only had access to a few items that do not directly translate to the definition of SLS, and these items have not been validated in previous research. To compensate for this, we performed a PCA, which improves accuracy and removes dimensions that 
only contribute noise; the PCA reduced the number of items into three meaningful components. About $10 \%$ of the adolescents in this cohort did not submit their declaration of health to the AFHRCC at the expected age. This may represent the most deprived adolescents, because non-participation or postponed submission is often due to mental illness. It is unknown if non-participation is linked to self-harm and healthcare contacts.

\section{Implications}

The results of this study are relevant to physicians and psychologists who provide clinical treatment to adolescents who engage in self-harm, as well as for prevention and future research. We argue that our results support previous suggestions that treatment and preventative strategies against self-harm must aim to teach adolescents how to regulate difficult emotions. ${ }^{39}$ Further, interventions that focus on increasing social functioning in self-harming adolescents by strengthening school participation, social relations, and coping may be less effective if emotional care is not also provided. ${ }^{25}{ }^{40}$ Because selfharm is associated with school absence, it can be difficult to reach adolescents who self-harm in school-based suicide prevention or life skills programmes. ${ }^{26}$ Our observations provide empirical evidence for further research on SLS and self-harm. More refined categories and validated instruments for SLS will maximise the possibilities of finding true differences between groups. Future investigations could focus on SLS among self-harming adolescents who go untreated compared with those who obtain help, which could be a valuable contribution to targeted interventions. Follow-up studies that investigate whether SLS in adolescence are related to morbidity and mortality later in life may clarify whether SLS improve outcomes in self-harming adolescents.

\section{Author affiliations}

${ }^{1}$ Institute of Military Epidemiology, Norwegian Armed Forces Joint Medical Services, Ullensaker, Akershus, Norway

${ }^{2}$ Centre for Fertility and Health, Norwegian Institute of Public Health, Oslo, Norway

${ }^{3}$ Department of Child and Adolescent Psychiatry, Oslo University Hospital, Oslo,

Norway

${ }^{4}$ Centre for Fertility and Health, Norwegian Institute of Public Health, 0slo, 0slo, Norway

${ }^{5}$ Institute of Community Medicine, UiT The Arctic University of Norway Faculty of Health Sciences, Tromso, Troms, Norway

${ }^{6}$ Regional Centre for Child and Youth Mental Health \& Child Welfare, UiT The Arctic University of Norway, Tromso, Norway

${ }^{7}$ Norwegian Command and Staff College, Norwegian Defence University College, Oslo, Norway

Acknowledgements We would like to acknowledge Trudy Perdrix-Thoma, Professional Standards Editing for language editing the manuscript.

Contributors All authors collaborated on the planning of the study. EKB had the responsibility for accessing data, (EØC) initially explored the data and facilitated for data analyses. EAF designed the study, performed the statistical analyses and drafted the manuscript. All authors contributed in the design of the study and the interpretation and reports of the results. The manuscript was circulated repeatedly between the authors for critical revisions. All authors have read and approved the final version of the manuscript. The view expressed in this article are those of the authors and are not necessarily those of the associated institutions. EAF accepts the full responsibility for the work.
Funding The authors have not declared a specific grant for this research from any funding agency in the public, commercial or not-for-profit sectors.

Competing interests None declared.

Patient and public involvement Patients and/or the public were not involved in the design, or conduct, or reporting, or dissemination plans of this research.

Patient consent for publication Not applicable.

Ethics approval The data for this study were taken from the NAFHR, which has approval to hold personal identifiable information for the Norwegian Armed Forces' personnel and conscripts, and to produce statistics and research in anonymous form without consent from the data subjects. Therefore, it was not necessary to obtain personal consent to participate in this study. Data analyses were conducted by employees of the Norwegian Army Joint Medical Services in accordance with the regulations of the NAFHR and international ethical guidelines for medical research.

Provenance and peer review Not commissioned; externally peer reviewed.

Data availability statement Data are available upon reasonable request. The data that support the findings of this study are available from The Norwegian Armed Forces Health Registry but restrictions apply to the availability of these data, which were used under license for the current study, and so are not publicly available. Data are however available from the authors upon reasonable request and with permission of The Norwegian Armed Forces Health Registry.

Open access This is an open access article distributed in accordance with the Creative Commons Attribution Non Commercial (CC BY-NC 4.0) license, which permits others to distribute, remix, adapt, build upon this work non-commercially, and license their derivative works on different terms, provided the original work is properly cited, appropriate credit is given, any changes made indicated, and the use is non-commercial. See: http://creativecommons.org/licenses/by-nc/4.0/.

ORCID iD

Elin Anita Fadum http://orcid.org/0000-0001-7751-5131

\section{REFERENCES}

1 Gillies D, Christou MA, Dixon AC, et al. Prevalence and characteristics of self-harm in adolescents: meta-analyses of community-based studies 1990-2015. J Am Acad Child Adolesc Psychiatry 2018;57:733-41.

2 Tørmoen AJ, Myhre M, Walby FA, et al. Change in prevalence of selfharm from 2002 to 2018 among Norwegian adolescents. Eur J Public Health 2020;30:688-92.

3 Borschmann R, Becker D, Coffey C, et al. 20-year outcomes in adolescents who self-harm: a population-based cohort study. Lancet Child Adolesc Health 2017;1:195-202.

4 Hawton K, Bale L, Brand F, et al. Mortality in children and adolescents following presentation to hospital after non-fatal self-harm in the multicentre study of self-harm: a prospective observational cohort study. Lancet Child Adolesc Health 2020;4:111-20.

5 Morgan C, Webb RT, Carr MJ, et al. Incidence, clinical management, and mortality risk following self harm among children and adolescents: cohort study in primary care. BMJ 2017;359:j4351.

6 Hawton K, Saunders KEA, O'Connor RC. Self-harm and suicide in adolescents. Lancet 2012;379:2373-82.

7 Abdelraheem M, McAloon J, Shand F. Mediating and moderating variables in the prediction of self-harm in young people: a systematic review of prospective longitudinal studies. J Affect Disord 2019;246:14-28.

8 Fliege H, Lee J-R, Grimm A, et al. Risk factors and correlates of deliberate self-harm behavior: a systematic review. J Psychosom Res 2009;66:477-93.

9 Kothgassner OD, Robinson K, Goreis A, et al. Does treatment method matter? A meta-analysis of the past 20 years of research on therapeutic interventions for self-harm and suicidal ideation in adolescents. Borderline Personal Disord Emot Dysregul 2020;7:9.

10 Asarnow JR, Berk MS, Bedics J, et al. Dialectical behavior therapy for suicidal self-harming youth: emotion regulation, mechanisms, and mediators. J Am Acad Child Adolesc Psychiatry 2021;60:1105-15.

11 Morken IS, Dahlgren A, Lunde I, et al. The effects of interventions preventing self-harm and suicide in children and adolescents: an overview of systematic reviews. F1000Res 2019;8:890.

12 Joiner TE. Why people die by suicide. Boston, MA: First Harvard University Press, 2005.

13 Durkheim E. Suicide: a study in sociology. Glencoe, IL: Free Press, 1951. 
14 Williams M. Cry of pain. understanding suicide and self-harm. London: Penguin Books, 1997.

15 Stack S. Suicide: a 15-year review of the sociological literature. Part I: cultural and economic factors. Suicide Life Threat Behav 2000;30:145-62

16 The World Health Organization. Regional framework for introducing Lifeskills education to promote the health of adolescents. Delhi: World Health Organization, 2001.

17 Oldershaw A, Grima E, Jollant F, et al. Decision making and problem solving in adolescents who deliberately self-harm. Psychol Med 2009;39:95-104.

18 Nrugham L, Holen A, Sund AM. Suicide attempters and repeaters: depression and coping: a prospective study of early adolescents followed up as young adults. J Nerv Ment Dis 2012;200:197-203.

19 McHugh CM, Chun Lee RS, Hermens DF, et al. Impulsivity in the selfharm and suicidal behavior of young people: a systematic review and meta-analysis. J Psychiatr Res 2019;116:51-60.

20 Heerde JA, Hemphill SA. Are bullying perpetration and victimization associated with adolescent deliberate self-harm? A meta-analysis. Arch Suicide Res 2019;23:353-81.

21 King CA, Merchant CR. Social and interpersonal factors relating to adolescent suicidality: a review of the literature. Arch Suicide Res 2008;12:181-96.

22 Rowe SL, French RS, Henderson C, et al. Help-seeking behaviour and adolescent self-harm: a systematic review. Aust N Z J Psychiatry 2014;48:1083-95.

23 Sellar C, Goldacre MJ, Hawton K. Reliability of routine hospital data on poisoning as measures of deliberate self poisoning in adolescents. J Epidemiol Community Health 1990;44:313-5.

24 Nasheeda A, Abdullah HB, Krauss SE, et al. A narrative systematic review of life skills education: effectiveness, research gaps and priorities. Int J Adolesc Youth 2019;24:362-79.

25 Jegannathan B, Dahlblom K, Kullgren G. Outcome of a school-based intervention to promote life-skills among young people in Cambodia. Asian J Psychiatr 2014;9:78-84.

26 Epstein S, Roberts E, Sedgwick R, et al. School absenteeism as a risk factor for self-harm and suicidal ideation in children and adolescents: a systematic review and meta-analysis. Eur Child Adolesc Psychiatry 2020;29:1175-94.

27 Ministry of Defense. Forskrift om Forsvarets Helseregister [Regulations concerning the collection and processing of data in the Norwegian Armed Forces health Registry]. Available: https://
lovdata.no/dokument/SF/forskrift/2005-09-02-1010?q=forsvarets $\%$ 20helseregister [Accessed 20 Apr 2020].

28 Ministry of Health and Care Services. The health register Act. ACT2014-06-20-43. Oslo: Lovdata, 2014.

29 Council for International Organizations of Medical Sciences. International ethical guidelines for health-related research involving humans. Geneva: Council for International Organizations of Medical Sciences, 2016.

30 Statistics Norway. Statbank. Population. 10211: Population, by sex and age 1846 - 2020. Oslo: Statistics Norway, 2020.

31 Jolliffe I. Principal component analysis. New York, NY: Springer Verlag, 2002.

32 Cohen J. Statistical power analysis for the behavioral sciences. Hillsdale, NJ: Erlbaum Associates, 1988.

33 Daniel SS, Goldston DB, Erkanli A, et al. Trait anger, anger expression, and suicide attempts among adolescents and young adults: a prospective study. $\mathrm{J}$ Clin Child Adolesc Psychol 2009;38:661-71.

34 Gulliver A, Griffiths KM, Christensen H. Perceived barriers and facilitators to mental health help-seeking in young people: a systematic review. BMC Psychiatry 2010;10:113.

35 Ystgaard M, Arensman E, Hawton K, et al. Deliberate selfharm in adolescents: comparison between those who receive help following self-harm and those who do not. J Adolesc 2009;32:875-91.

36 Green JD, Jakupcak M. Masculinity and men's self-harm behaviors: Implications for non-suicidal self-injury disorder. Psychol Men Masc 2016:17:147-55.

37 Windle M. A longitudinal study of antisocial behaviors in early adolescence as predictors of late adolescent substance use: gender and ethnic group differences. J Abnorm Psychol 1990;99:86-91.

38 Fadum EA, Stanley B, Qin P, et al. Self-poisoning with medications in adolescents: a national register study of hospital admissions and readmissions. Gen Hosp Psychiatry 2014;36:709-15.

39 Neacsiu AD, Bohus M, Linehan M. Dialectical behvior therapy: An intervention for emotion dysregulation. In: Gross JJ, ed. Handbook of emotion regulation. New York: The Guilford Press, 2015: 491-507.

40 Johnstone JM, Ribbers A, Jenkins D, et al. Classroom-based mindfulness training reduces anxiety in adolescents: acceptability and effectiveness of a cluster-randomized pilot study. J Restor Med 2020;10. doi:10.14200/jrm.2020.0101. [Epub ahead of print: $20 \mathrm{Jul}$ 2020] 